\title{
Relationship between the expression of CES2, UGT1A1, and GUSB in colorectal cancer tissues and aberrant methylation
}

\author{
F. W. XIE, Y. PENG, X. CHEN, X. CHEN, J. LI, W. WANG, Z. YU, X. OUYANG* \\ Department of Medicine Oncology, Fuzhou General Hospital of Nanjing Military Command, Fuzhou, Fujian, China \\ *Correspondence: oyxn@public.fz.fj.cn
}

Received December 22, 2013 / Accepted July 09, 2013

\begin{abstract}
Irinotecan (CPT-11) is considered an important drug in the treatment of colorectal cancer, but its continuous administration reduces its sensitivity and influences the curative effect. The metabolism of CPT-11 is mainly controlled by carboxy-lesterase (CES), UDP-glucuronosyltransferase 1A (UGT1A), and $\beta$-glucuronidase (GUSB). Studies to date have shown that methylation acts as an important mechanism for gene expression to suppress the metabolic enzymes of many chemotherapeutics. This study, which selected 99 colorectal cancer patients, 23 of whom had paracancerous tissues and eight of whom had large intestine adenomas, aimed to investigate the correlation between the protein expression of the CPT-11 metabolic enzyme genes CES2, UGT1A1, and GUSB and various clinical pathological parameters of colorectal cancer tissues, as well as the relationship between methylation regulation and the gene expression of CES2, UGT1A1, and GUSB. We used immunohistochemistry staining, methylation-specific PCR, and clinical status to reveal the possible regulatory targets of chemotherapeutic resistance in colorectal cancer and to provide new ideas and countermeasures to reverse anti-cancer drug resistance and chemosensitization. The results showed that the expression of CES2, UGTA1A1, and GUSB varies in colorectal pathology tissues and that the expression of CES2 is somewhat related to tumor staging. This relationship is likely caused by the gene regulation of $U G T 1 A 1$ and GUSB, and other regulation mechanisms may also be involved. The methylation of the CES 2 gene is irrelevant to the morbidity associated with colorectal cancer. The GUSB gene showed no significant differences in methylation, and the hemi-methylation was also positive, the regulating ability of which needs to be verified. The potential role of these genes in the colorectal cancer progresion, which may be directly related to the methylation regulation of UGT1A1, requires further research. The promoter of the UGT1A1 gene in colorectal cancer cells is methylated, which is an important mechanism of UGT1A1 gene silencing and can be regarded as the target point of research for CPT-11 drug resistance and control mechanisms for the reversal of drug resistance.
\end{abstract}

Key words: colorectal cancer, DNA methylation, CES2, UGT1A1, GUSB, CPT-11

Colorectal cancer is considered to be a malignant tumor with one of the highest incidence and mortality rates. In late, recurrent, or metastatic colorectal cancer cases, pharmacotherapy serves as the main strategy for current chemotherapy. Current studies on the drugs used in the treatment of colorectal cancer have mainly focused on the screening of new target points, such as the epidermal growth factor receptor (EGFR) inhibitor and cyclooxygenase (COX)-2 inhibitor, which have demonstrated good therapeutic effects in the initial stage of therapy. However, along with the development of drug resistance, the therapeutic effects also vary between these drugs. The drug resistance gene mechanism has always been the focus of relevant studies; however, desired effects have not yet been achieved, and an effective therapeutic method that can reverse drug resistance has not yet been developed. Therefore, targeted research on drug resistance has rapidly increased in relevant fields.

Aberrant methylation is one of the phenotypes of tumor cells. Hypomethylation defects are very common in malignant tumors $[1,2]$, especially in solid tumors such as metastasizing hepatocellular carcinoma, cervical cancer, and prostate cancer [3-5]. The degree of hypomethylation defects is directly related to the grade of malignancy [6], and hypomethylation can activate proto-oncogenes and cause abnormal expression. Current studies have confirmed that the genomic instability caused by the general hypomethylation of DNA is one of the causes of tumor formation $[7,8]$. Researchers have also found that chromosome demethylation caused by the mutation of 




Figure 1. The metabolism process of CPT-11 in liver.

DNA methyltransferase (DNMT) may lead to the genomic instability of mice and lymphoma $[7,9]$. Gene silencing that results from over-methylation may lead to drug resistance. An analogue of deoxycytosine, decitabine, has been recently developed to address over-methylation. This drug can reverse drug resistance [10] by inhibiting the hypermethylation state of the DNMT-relevant gene promoter and topoisomerase. The target points regulated and controlled by methylation have shown new vitality in drug resistance studies, and the screening of these targets and verification of their functions have been the emphasis of relevant studies.

Irinotecan (CPT-11) has been considered a main drug in the treatment of colorectal cancer in recent years, but CPT-11 commonly shows insensitivity to chemotherapy treatment in colorectal cancer. Irinotecan and its metabolites are mainly cleared by the liver, and only a small amount $(<20 \%)$ is cleared by the kidney. It is further hydrolyzed by carboxy-lesterase (CES) in the liver tissue and changed into its active metabolite, $\mathrm{SN}-38$, which is then inactivated to the inactive conjugate $\mathrm{SN}$ 38 G by the UDP-glucuronosyltransferase 1A (UGT1A) glucose aldehyde group before being excreted to the enteric cavity through the bile. Some SN-38G is changed into SN38 after losing a glucose aldehyde group as a result of GUSB (Fig. 1). The GUSB in the tumor tissue also participates in this process.

Therefore, the regulation and control of the expression of CPT-11 metabolic enzymes inside colorectal cancer cells are directly related to the concentration of $\mathrm{SN}-38$, which in turn affects the curative effect of chemotherapeutics. Many chemotherapeutic metabolic enzymes cause epigeneticgene silencing, whereas methylation is most likely an important mechanism associated with the regulation and control of the gene expression of these enzymes. This paper explores the correlation between the relevant gene expression of CPT-11 metabolic enzymes and the pathological development of colorectal cancer.Furthermore, this study investigated a potential regulatory methylation mechanism associated with these genes and aimed to reveal the possible regulatory target points of chemotherapeutic resistance in colorectal cancer. These findings should provide new insights and countermeasures relevant to the reversal of anti-cancer drug resistance and chemosensitization.

\section{Materials and methods}

Pathological samples. All tumor samples were collected from patients diagnosed with colorectal cancer at Southwest Hospital from 2003 to 2008, including 99 samples of surgically excised tumors, 23 paracancerous samples, and eight colorectal adenoma samples. The detailed clinical data, surgical records, and pathological records of all patients were also provided. Patients with adenocarcinomas did not receive radiotherapy or chemotherapy before the operation. Among the 99 colorectal cancer patients, 52 were male and 44 were female. The cohort age ranged from 25 to 86 years, with an average age of $55.77 \pm 13.70$ years; 52 patients were under the age of 60 years, and the remaining 47 patients were over the age of 60 years. The cohort included 60 cases of rectal cancer and 39 cases of colon cancer. A total of 80 patients exhibited highly and medium-differentiated tumors, and 19 patients exhibited low-differentiated tumors. According to the staging of colorectal cancer determined by AJCC (2002), 28 cases were Stage A colorectal cancer, 31 cases were Stage B colorectal cancer, 27 cases were Stage $\mathrm{C}$ colorectal cancer, and 37 cases were Stage D colorectal cancer.

Immunohistochemical staining. The immunohistochemistry staining was performed on $6-\mu \mathrm{m}$-thick paraffin sections. The paraffin section were dewaxed in xylene and rehydrated via gradient ethanol immersions, followed by an incubation in methanol containing $3 \% \mathrm{H}_{2} \mathrm{O}_{2}$ for 10 min to inactivate endogenous peroxidase. This inactivation was followed by washing the sections three times for $5 \mathrm{~min}$ in phosphate-buffered saline (PBS). The antigen was retrieved by boiling the samples in citrate buffer ( $\mathrm{pH}$ 6.0) for $15 \mathrm{~min}$, followed by blocking with $10 \%$ normal fetal bovine serum (FBS) before incubating them with a primary or polyclonal antibody (diluted in blocking 
buffer) in a humid chamber at $37^{\circ} \mathrm{C}$ for $1 \mathrm{~h}$. The samples were then incubated with rabbit anti-human CES2 (1:500), goat anti-human UGT1A1, or goat anti-human GUSB overnight at $4^{\circ} \mathrm{C}$ in a humid chamber and washed three times for $5 \mathrm{~min}$ in PBS. The antigen was incubated for $30 \mathrm{~min}$ at $37^{\circ} \mathrm{C}$ with Envison+, peroxidase, rabbit IgG(1:200 dilution), followed by washing with PBS. The antibodies and working dilutions used in this study are listed in Table 1 . The reaction product was visualized with diaminobenzidine (DAB, ZLI-9032, ZSGB; Beijing, China) as a chromogen substrate at room temperature for $5 \mathrm{~min}$. Finally, stained sections were briefly (20 s) counterstained with hematoxylin (ZLI-9039, ZSGB; Beijing, China), followed by rinsing in running tap water for $15 \mathrm{~min}$. The samples were then dehydrated, cleared with xylene, and mounted in Permount (Thermo Fisher Scientific, USA). The staining was visualized under a light microscope (Olympus BX51, Olympus, Japan), and the images were captured using a DP70 digital camera. For all antibodies tested, positive and negative tissues were utilized as positive and negative controls, respectively.

Evaluation of immunohistochemical staining. Immunohistochemical staining involves the use of known positive samples as a positive control and substitutes the primary antibody with $\mathrm{PBS}$ as a negative control. Five random views ( $\times 400$ magnification) from each pathological section were selected to evaluate the results. The evaluation was based on the staining intensity and percentage of positive cells. Specifically, the color intensity (yellowish brown) correlated positively with the degree of antibody fixation, and a higher degree of antibody fixation indicated an increased presence of the target protein; namely, positive cells presented a color change with antibody fixation. The percentage of positive cells can reflect the primary expression and intensity of the tested proteins. The expression of the protein of interest was determined based on a comprehensive score:

1. Staining intensity: colorless, score of 0 ; faint yellow, score of 1 ; brown-yellow, score of 2; and yellowish-brown, score of 3;

2. Number of positive cells: this score was based on 200 cancer cells on each section, assessed in five views. If the number of positive cells did not exceed $10 \%$, the score was 0 ; if the number of positive cells was between 11 and $25 \%$, the score was 1; if this number was between 26 and $50 \%$, the score was 2; and if this number was between 51 and $100 \%$, the score was 3 .

Based on the product of these two scores, the comprehensive score was determined as follows: values between 0 and 3 were deemed (-); a score of 4 was deemed (+); a score of 6 was deemed $(++)$; and a score of 9 was deemed $(+++)$.

Methylation-specific PCR. The MSP primers were designed in strict accordance with the following principles: 1 . The primer sequence contained at least one $\mathrm{CpG}$ island. Furthermore, this $\mathrm{CpG}$ island was located near the 3 ' region. 2. The primer sequences contained many $\mathrm{C}$-terminals without $\mathrm{CpG}$ islands. 3. Both the number and position of the $\mathrm{CpG}$ island were identical in the methylated and unmethylated DNA primers. 4. Other principles were consistent with those associated with regular PCR. The DNA of the placental gene group has been proven to be unmethylated. The placental DNA that regulates M.SssI methyltransferase was modified using the DNA CpG island methylation modification kit, and PCR amplification was used as a positive control for methylation. The placental DNA that does not regulates M.SssI methyltransferase was modified using the DNA CpG island methylation modification kit, and PCR amplification was used as the non-methylation positive control. The methylation-specific PCR could amplify the proposed methylation sequence via a specific primer, while the unmethylated sequence could not be amplified. According to the positive control of the two groups of placental DNA, the likely DNA gene associated with methylation status could be determined. Total RNA was prepared according to the manufacturer's instructions. After DNase I treatment, $2 \mu \mathrm{g}$ of RNA was reverse-transcribed with AMV reverse transcriptase. The DNA of the placental gene group was extracted (DNA Easy Kit, Qiagen, Germany) and divided into two groups, and $\mathrm{H}_{2} \mathrm{O}$ was added to $40 \mu \mathrm{L}$ of one group with $4 \mu \mathrm{L}$ of $10 \times \mathrm{NEB}$ Buffer, $0.2 \mu \mathrm{L}$ of SAM (32 mM), $2 \mathrm{U}$ of Sss I Methylase, and $2 \mu \mathrm{g}$ of DNA. The mixture was then incubated in a water bath at $37^{\circ} \mathrm{C}$ for $3 \mathrm{~h}$ to induce methylation. Next, $2 \mu \mathrm{g}$ of DNA from each gene group was then modified with hydrosulphite (EZ DNA Methylation Kit, ZYMO, Germany). The hydrosulphite can enable deamination in the unmethylated cytosine in the DNA sequence and transform it to uracil, while methylated cytosine cannot be deaminated. The treated placental DNA would have underwent the PCR-amplified reaction in the same system as the sample DNA. A master mixture containing the reaction buffer, dNTPs, Taq polymerase, and $1.6 \mu \mathrm{L}$ of cDNA in $20 \mu \mathrm{L}$ of reaction mixture was transferred to different PCR tubes. The reaction conditions were defined as follows: $94^{\circ} \mathrm{C}$ for $3 \mathrm{~min}$, $94^{\circ} \mathrm{C}$ for $30 \mathrm{~s}$, and $53^{\circ} \mathrm{C}$ for $30 \mathrm{~s}$ for 30 cycles, followed by $72^{\circ} \mathrm{C}$ for $40 \mathrm{~s}$ and $72^{\circ} \mathrm{C}$ for $5 \mathrm{~min}$. The forward and reverse primers corresponding to different individual genes were added to the PCR tubes and subjected to PCR amplification using primer sets directed against CES2 M/UGT1A1 M /GUSB M and CES2 $\mathrm{U} / \mathrm{UGT} 1 \mathrm{~A} 1 \mathrm{U} / \mathrm{GUSB} \mathrm{U}$. The annealing temperature was $53^{\circ} \mathrm{C}$ for these primers, which are shown in Table 2. The specific methylated primer could only amplify the methylation strip, while the specific unmethylated primer could only amplify the unmethylated strip, i.e., each sample could amplify only one strip. When the methylated and unmethylated products were simultaneously amplified in a specimen, the sample was considered to be hemimethylated. Hemimethylation is also called positive methylation.

Table 1. Primary or polyclonal antibodies for immunohistochemical staining in colorectal cancer tissues and normal tissues.

\begin{tabular}{lcccc}
\hline Antibody & Host & Dilution & Company & Catalog number \\
\hline CES2 & rabbit & $1: 500$ & Santa Cruz & sc-33739 \\
UGT1A1 & goat & $1: 200$ & Santa Cruz & sc-27415 \\
GUSB & goat & $1: 200$ & Santa Cruz & sc-26282 \\
\hline
\end{tabular}


Table 2 PCR primers for CES2,UGT1A1 and GUSB gene

\begin{tabular}{lllc}
\hline Name of primer & Sence primer & Antisence primer & Size $(\mathrm{bp})$ \\
\hline CES $2 / \mathrm{M}$ & GTCGTTATAGGTCGTTTTTTAGAGC & CAACGATAATAATTCCGCGAT & 108 \\
CES $2 / \mathrm{U}$ & TGTTATAGGTTGTTTTTTAGAGTGT & AAATCAACAATAATAATTCCACAAT & 110 \\
UGT1A1/M & AATATAAGGTAGGTAGGTTTTACGG & TTTTATAATTAAAATTTTCAACGCT & 211 \\
UGT1A1/U & AATATAAGGTAGGTAGGTTTTATGG & TTTTATAATTAAAATTTTCAACACT & 211 \\
GUSB $/ \mathrm{M}$ & TGGGGAGTAGATTTCGTTTTTATC & GTAATACGCCTAAAACCATCCG & 173 \\
GUSB/U & GGGAGTAGATTTTGTTTTTATTGG & TCATAATACACCTAAAACCATCCAC & 173 \\
\hline
\end{tabular}

${ }^{*}$ M:methylation ${ }^{* *} \mathrm{U}:$ unmethylation

Statistical analysis. Each experiment was repeated at least twice, and each data point represents the mean of at least three parallel samples. The Pearson chi-square test was adopted to test the relationship between the protein expressions of CES2, GUSB, and UGT1A1 and clinicopathological indicators. A paired-data chi-square test was adopted to test the relationship between the expressions of CES2, UGT1A1, and GUSB in colorectal cancer tissues and paracancerous normal tissues. A paired-data chi-square and kappa test were also adopted to test the consistency between the methylation state of the promoter and the protein expression. The SPSS 13.0 software was used for the statistical analysis (SPSS, Inc.), and $P<0.05$ indicated a significant difference.

\section{Results}

Pathological analysis on random pathological sections of colorectal cancer. Two randomly selected sections were identified as tubular adenomas based on the obvious pathological characteristics of tubular adenoma visualized via the HE staining of the paraffin sections of 99 cases of colorectal cancer, 23 of which were paracancerous normal tissues and eight of which were adenoma tissues. These sections showed chambers of different sizes with mucus in them, and their epithelia matched and exhibited an irregular tubule-type shape, a long and narrow trabecular lumen, or a lack of myoepithelial cells in the trabecular periphery. The sample was loosely attached to the mesenchyme, which showed a large number of blood capillaries and venules. The parenchyma and mesenchyme were separated by the basilar membrane (Fig. $2 \mathrm{~A}$ and B). All pathological results were consistent with the original diagnosis. The samples could be used to research the relationship between the gene expressions of CES2, UGT1A1, and GUSB in colorectal cancer tissues and aberrant methylation.

The expression levels of CES2, UGT1 A1, and GUSB in the colorectal cancer tissues and normal tissues. Commercially available antibodies against colorectal cancer tissue and normal tissue markers for other species have not been evaluated in humans. Thus, we chose the antibodies listed in Table 1. The results showed that the positive signals of CES2, UGT1A1,

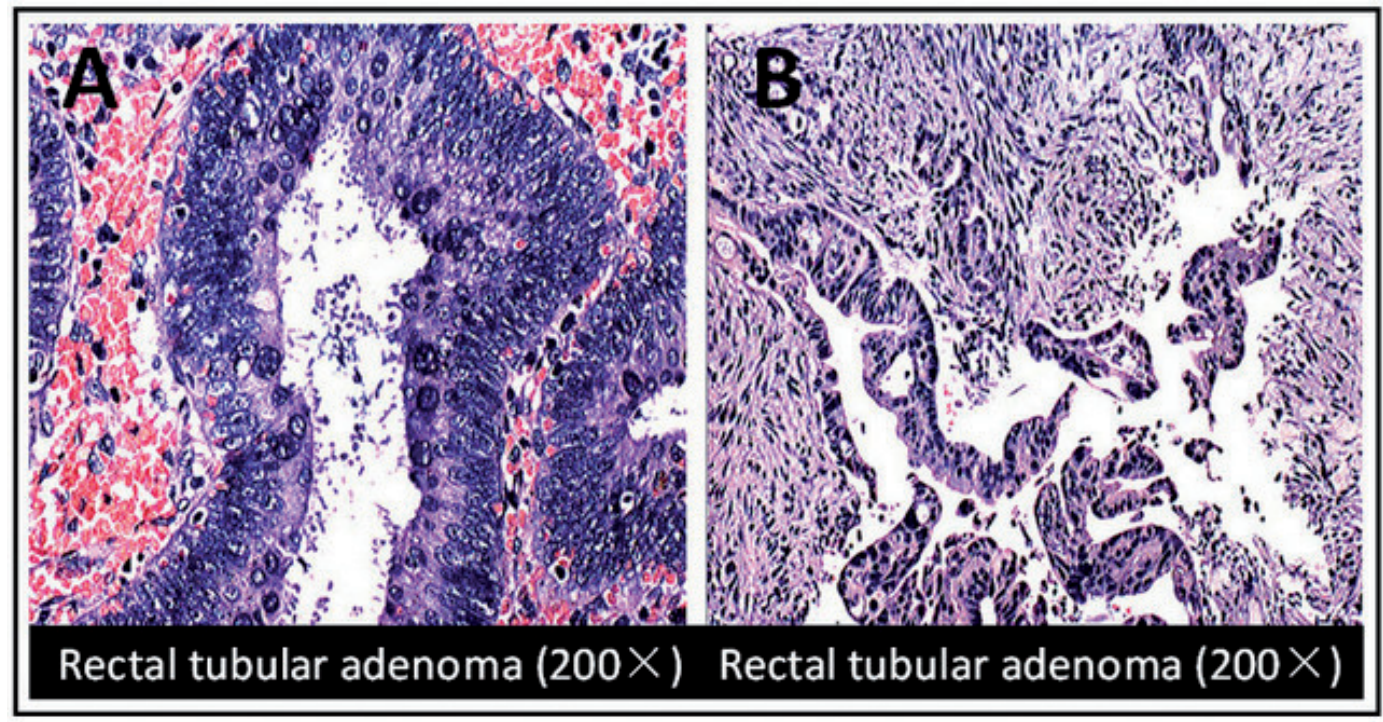

Figure 2. Hematoxylin-eosin staining (HE). A, B are the two randomly selected samples in 99 cases of rectal tubular adenoma and adenocarcinoma after HE staining and sectioning. (A) Rectal tubular adenoma, (B) Rectal tubular adenocarcinoma 
and GUSB protein presented as faint yellow to tawny particles. Among the representative samples, the faint brown-yellow particles indicating CES2, UGT1A1, and GUSB suffused in the cytoplasm and focused on the mucous epithelium of the intestine, with no expression in the cell membrane or karyon. However, the expression of GUSB in the intestinal mesenchyme lymphocytes was higher than that in normal tissues (Fig. 3 A-I). Among the 99 cases of colorectal cancer and 23 cases of paracancerous normal tissues, the positive expression rates of UGT1A1, CES2, and GUSB in the colorectal cancer cells were $18.18,40.4$, and $45.45 \%$, respectively, while the positive rates were $34.78,56.52$, and $47.83 \%$, respectively, in the paracancerous normal tissues. The positive gene expression rates of the latter three were clearly higher than those of the former. A non-parametric test of two relevant samples (chi-square test via paired data) was adopted to analyze the expression of the aforementioned three types of genes in the intestinal cancer and paracancerous tissues. The expression levels of CES2 and UGT1A1 in the above two tissues were significantly different $(\mathrm{P}<0.05)$. The expression of GUSB was different in the two tissues, but this difference was not statistically significant $(\mathrm{P}>0.05)$. These findings suggest that the two
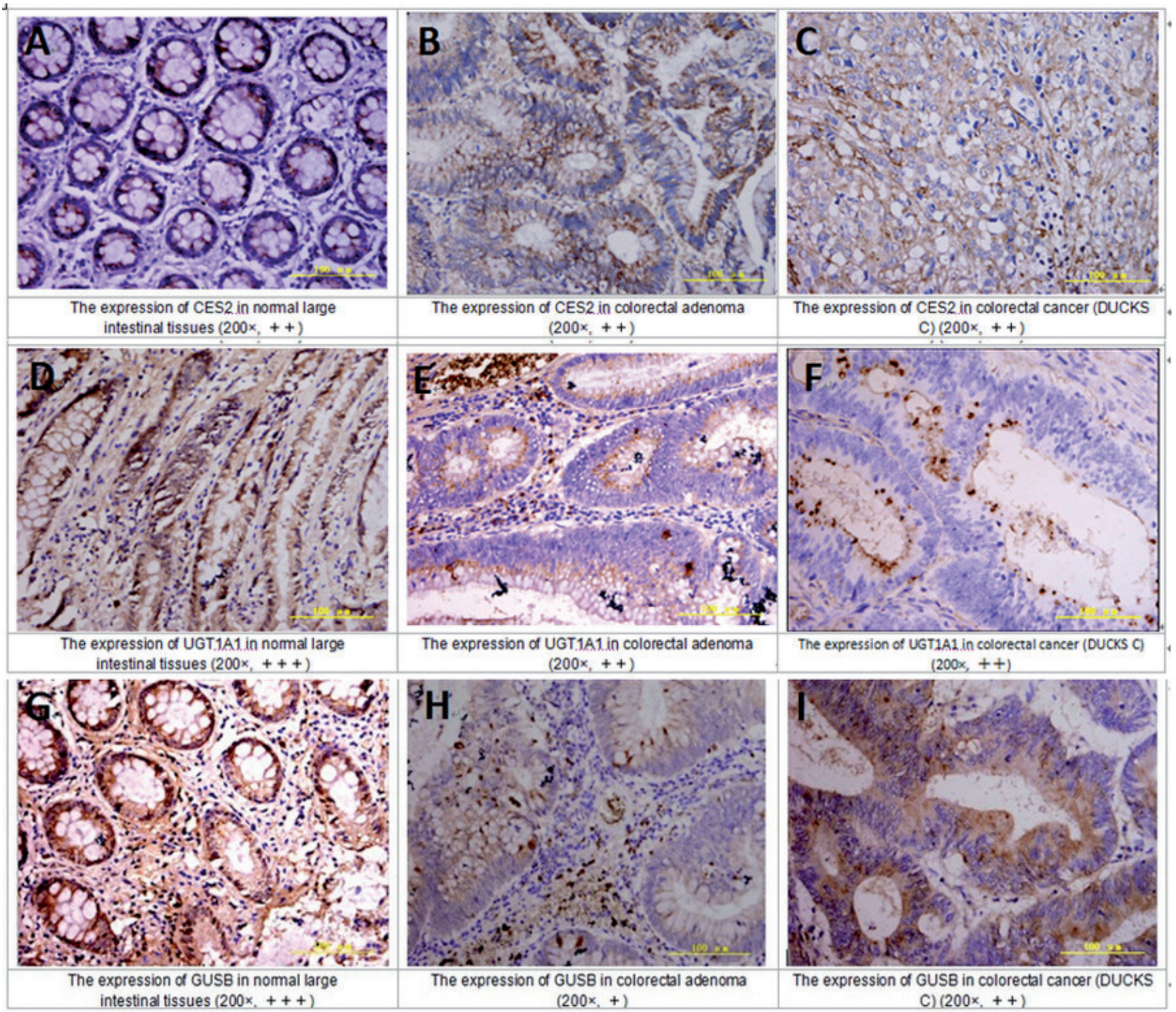

Figure 3. Immunohistochemical staining of the expression of CES2, UGT1A1 and GUSB in the colorectal cancer tissues and normal tissues. (A - I) Representative image of immunohistochemical staining of (A) the expression of CES2 in normal large intestinal tissues, (B) the expression of CES2 in colorectal adenoma, (C) the expression of CES2 in colorectal cancer (DUCKS C), (D) the expression of UGT1 A1 in normal large intestinal tissues, (E) the expression of UGT1 A1 in colorectal adenoma, (F) the expression of UGT1A1 in colorectal cancer (DUCKS C), (G) the expression of GUSB in normal large intestinal tissues, (H) the expression of GUSB in colorectal adenoma, (I) the expression of GUSB in colorectal cancer. Scale bar $=100 \mu \mathrm{m}$. 
Table 3. The expression of CES2, UGT1A1and GUSB in colorectal tissues

\begin{tabular}{|c|c|c|c|c|c|c|c|}
\hline \multirow[b]{2}{*}{ Types of tissues } & \multirow[b]{2}{*}{$\mathrm{N}$} & \multicolumn{2}{|c|}{ Expression of UGT1A1 } & \multicolumn{2}{|c|}{ Expression of CES2 } & \multicolumn{2}{|c|}{ Expression of GUSB } \\
\hline & & $\begin{array}{c}0 \sim+ \\
\mathrm{n}(\%)\end{array}$ & $\begin{array}{c}++\sim+++ \\
\mathrm{n}(\%)\end{array}$ & $\begin{array}{c}0 \sim+ \\
\text { n (\%) }\end{array}$ & $\begin{array}{c}++\sim+++ \\
\mathrm{n}(\%)\end{array}$ & $\begin{array}{c}0 \sim+ \\
\mathrm{n}(\%)\end{array}$ & $\begin{array}{c}++\sim+++ \\
\mathrm{n}(\%)\end{array}$ \\
\hline Colorectal cancer tissues & 99 & $81(82 \%)$ & $18(18 \%)$ & $59(60 \%)$ & $40(40 \%)$ & $13(55 \%)$ & $45(45 \%)$ \\
\hline Paracancerous normal tissues & 23 & $15(65 \%)$ & $8(35 \%)$ & $10(43 \%)$ & $13(57 \%)$ & $12(52 \%)$ & $11(48 \%)$ \\
\hline$P$ value & & \multicolumn{2}{|c|}{$\mathrm{P}=0.017$} & \multicolumn{2}{|c|}{$\mathrm{P}=0.048$} & \multicolumn{2}{|c|}{$\mathrm{P}=0.436$} \\
\hline
\end{tabular}

genes, CES2 and UGT1A1, show regular changes in cancer tissues, which may be caused by methylation (Table 3 ).

3.3 The relationship between the expression of CES2, UGT1A1, and GUSB in colorectal cancer, paracancerous, and adenoma tissues and the clinical pathological parameters of patients with colorectal cancer

A total of 99 cases of colorectal cancer patients with complete clinical data were grouped according to, for example, the patients' gender and age, tumor location, tissue type, differentiation, and staging. The gender, age, tumor location, tissue type, and differentiation did not obviously correlate with the expression levels of CES2, UGT1A1, and GUSB as assessed by a chi-square test $(\mathrm{P}>0.05)$. However, the expression of CES2 showed statistically significant differences between different stages $(\mathrm{P}<0.01)$. The data indicated that the staging of colorectal cancer was a function of the expression of
CES2: the later the staging, the lower the expression rate of CES2 (Table 4). However, the immunohistochemical staining proved that the expression of CES2 and UGT1A1 differed in normal tissues. Therefore, the expression of CES2 should be changed as a result of changes in its regulation after tumor development. Specifically, UGT1A1 regulates its expression in the presence of a tumor. Thus, the development and metastasis of the tumor would not cause secondary regulation [11]. The data also indicated that the expression of three types of genes was the result of a relatively independent regulatory progress without any correlation.

Analysis of the methylation of CES2, UGT1A1, and GUSB genes in carcinoma tissues of colorectal cancer patients. After conducting a CES2, UGT1A1, and GUSB gene promoter methylation test for the 99 colorectal cancer samples, MSP agarose gel electrophoresis was also performed on 23 color-

Table 4. The relationship between the expression of CES2, UGT1A1 and GUSB in various colorectal tissues and the clinical parameters

\begin{tabular}{|c|c|c|c|c|c|c|c|c|c|c|}
\hline \multirow[b]{2}{*}{ Clinical parameters } & \multirow[b]{2}{*}{$\mathrm{N}$} & \multicolumn{3}{|c|}{ UGT1A1 expression } & \multicolumn{3}{|c|}{ CES2 expression } & \multicolumn{3}{|c|}{ GUSB expression } \\
\hline & & $\begin{array}{c}0 \sim+ \\
\mathrm{n}(\%)\end{array}$ & $\begin{array}{c}++\sim \\
+++ \\
\mathrm{n}(\%)\end{array}$ & $\begin{array}{c}\mathrm{P} \\
\text { value }\end{array}$ & $\begin{array}{c}0 \sim+ \\
\mathrm{n}(\%)\end{array}$ & $\begin{array}{c}++\sim \\
+++ \\
\mathrm{n}(\%)\end{array}$ & $\begin{array}{c}\mathrm{P} \\
\text { value }\end{array}$ & $\begin{array}{c}0 \sim+ \\
\mathrm{n}(\%)\end{array}$ & $\begin{array}{c}++\sim \\
+++ \\
\mathrm{n}(\%)\end{array}$ & $\begin{array}{c}\mathrm{P} \\
\text { value }\end{array}$ \\
\hline \multicolumn{11}{|l|}{ Sex } \\
\hline Male & 52 & $42(85 \%)$ & $8(15 \%)$ & \multirow{2}{*}{0.684} & $36(69 \%)$ & $16(31 \%)$ & \multirow{2}{*}{0.316} & $32(62 \%)$ & $20(38 \%)$ & \multirow{2}{*}{0.987} \\
\hline Female & 47 & $38(81 \%)$ & $9(19 \%)$ & & $28(60 \%)$ & $19(40 \%)$ & & $29(62 \%)$ & $18(38 \%)$ & \\
\hline \multicolumn{11}{|l|}{ Age } \\
\hline$<60$ & 52 & $45(87 \%)$ & $7(13 \%)$ & \multirow{2}{*}{0.128} & $32(62 \%)$ & $20(38 \%)$ & \multirow{2}{*}{0.496} & $29(56 \%)$ & $23(44 \%)$ & \multirow{2}{*}{0.208} \\
\hline$\geq 60$ & 47 & $35(74 \%)$ & $12(26 \%)$ & & $32(77 \%)$ & $15(23 \%)$ & & $32(68 \%)$ & $15(32 \%)$ & \\
\hline \multicolumn{11}{|l|}{ Position } \\
\hline Colon & 39 & $33(85 \%)$ & $6(15 \%)$ & \multirow{2}{*}{0.438} & $24(62 \%)$ & $15(38 \%)$ & \multirow{2}{*}{0.602} & $24(62 \%)$ & $15(38 \%)$ & \multirow{2}{*}{0.990} \\
\hline Rectum & 60 & $47(78 \%)$ & $13(22 \%)$ & & $40(67 \%)$ & $20(33 \%)$ & & $37(62 \%)$ & $23(38 \%)$ & \\
\hline \multicolumn{11}{|l|}{ Types of tissues } \\
\hline Colorectal cancer tissues & 99 & $80(81 \%)$ & $19(19 \%)$ & \multirow{3}{*}{0.268} & $64(65 \%)$ & $35(35 \%)$ & \multirow{3}{*}{0.149} & $61(62 \%)$ & $38(38 \%)$ & \multirow{3}{*}{0.612} \\
\hline Paracancerous normal tissues & 23 & $15(65 \%)$ & $8(35 \%)$ & & $10(43 \%)$ & $13(57 \%)$ & & $12(52 \%)$ & $11(48 \%)$ & \\
\hline Adenoma & 8 & $6(75 \%)$ & $2(25 \%)$ & & $4(50 \%)$ & $4(50 \% 0$ & & $4(50 \%)$ & $4(50 \%)$ & \\
\hline \multicolumn{11}{|l|}{ Differentiation } \\
\hline High and middle differentiation & 80 & $63(79 \%)$ & $17(21 \%)$ & \multirow{2}{*}{0.458} & $49(61 \%)$ & $31(39 \%)$ & \multirow{2}{*}{0.147} & $52(65 \%)$ & $28(35 \%)$ & \multirow{2}{*}{0.155} \\
\hline Low differentiation & 19 & $17(89 \%)$ & $2(11 \%)$ & & $15(79 \%)$ & $4(21 \%)$ & & $9(47 \%)$ & $10(53 \%)$ & \\
\hline DUCKS staging $\mathrm{A}+\mathrm{B}$ & 59 & $48(81 \%)$ & $11(19 \%)$ & \multirow{2}{*}{0.866} & $24(41 \%)$ & $35(59 \%)$ & \multirow{2}{*}{0.000} & $34(58 \%)$ & $25(42 \%)$ & \multirow{2}{*}{0.322} \\
\hline DUCKS staging $\mathrm{C}+\mathrm{D}$ & 40 & $32(80 \%)$ & $8(20 \%)$ & & $38(95 \%)$ & $2(5 \%)$ & & $27(67 \%)$ & $13(33 \%)$ & \\
\hline
\end{tabular}


ectal cancer pericarcinomatous tissues. The sample figures are typical, showing the positive control, negative control, and hemimethylation (Figs. 4-6 and Table 5).

The results showed that CES2 was unmethylation-positive (USP, +) in 99 colorectal cancer samples, methylation-negative
(MSP, -) in 95 samples, and hemimethylated in four samples. The 23 paracancerous normal tissue samples were all MSPnegative and USP-positive. In the 99 colorectal cancer samples, UGT1A 1 was methylation-positive in $85.9 \%$ of cases $(85 / 99)$. In paracancerous tissues, this rate was reduced to $65.2 \%(15 /$

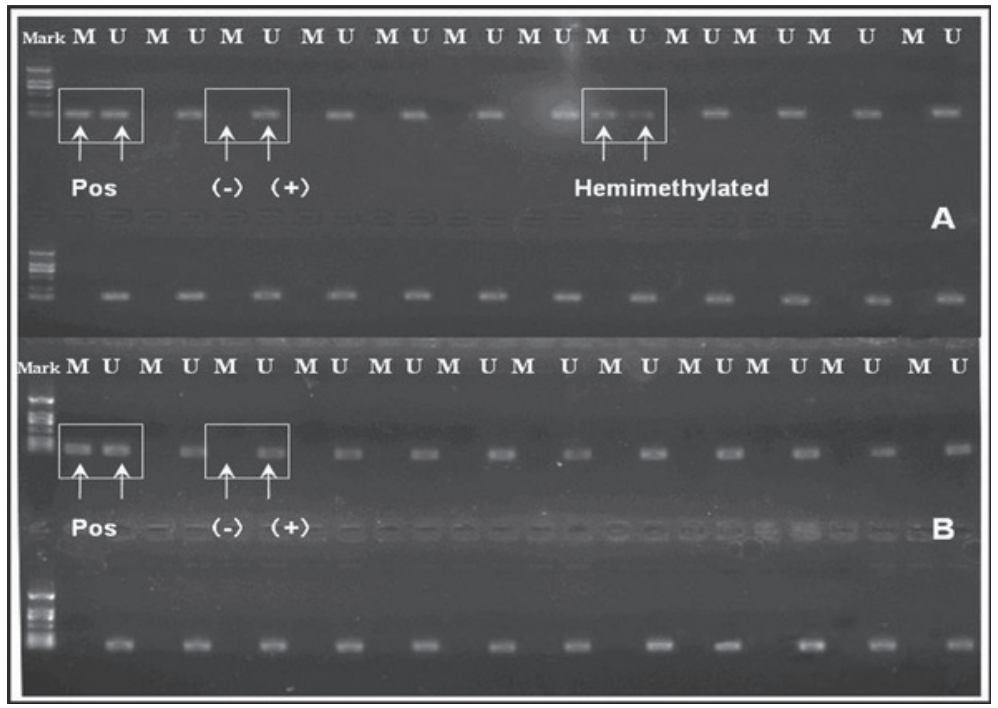

Figure 4. MSP Agarose Gel Electrophoresis of Colorectal Cancer Tissues and Paracancerous Normal Tissues Ces2 Gene (1.5\%). A. Colorectal Cancer Tissues (Number 1-23 Sample). B. Paracancerous Normal Tissues (23 cases). Pos: positive control (Modification of placenta after been dealt with M.Sss I and modification of placenta without dealing with M.Sss I); Marker (DL2000); M (MSP, methylated); U (USP, unmethylated). Area without strip is negative (-), area with strip is positive (+).CES2 all showed unmethylation positive (USP, +), while in 95 samples, CES2 all showed methylation negative (MSP,-), hemimethylation in 4 samples.

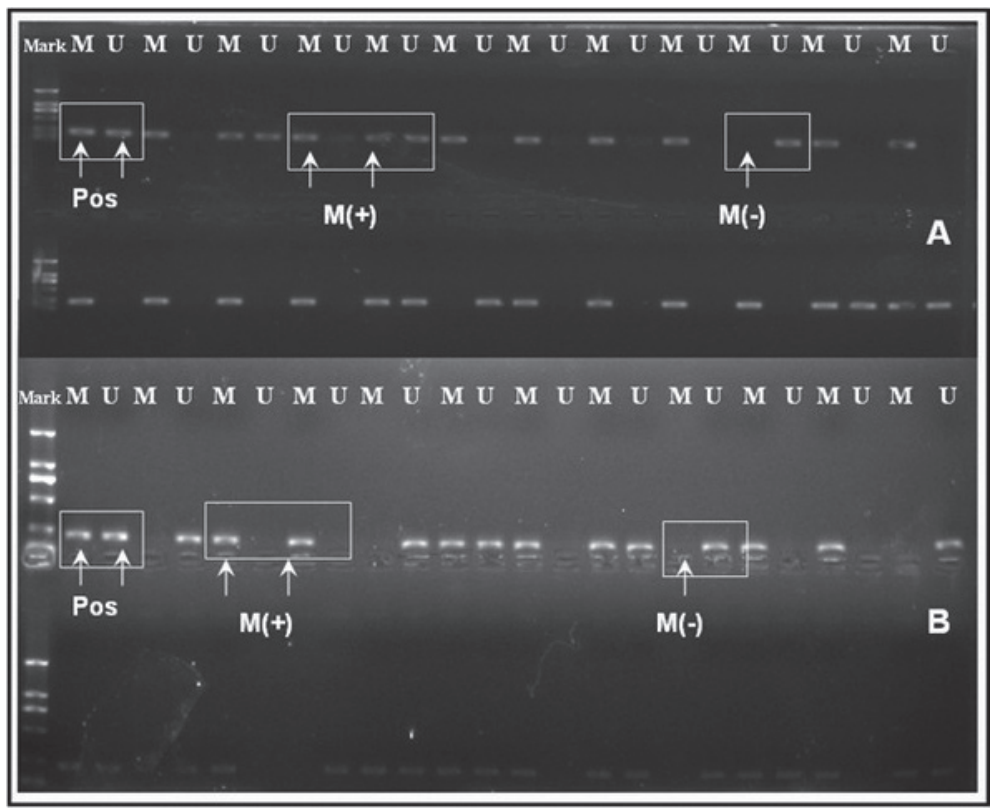

Figure 5. MSP Agarose Gel Electrophoresis of Colorectal Cancer Tissues and paracancerous normal tissues UGT1A1 Gene (1.5\%). A. Colorectal Cancer Tissues (Number 1-23 Sample). B. Paracancerous Normal Tissues (23 Cases). Pos: positive control (Modification of placenta after been dealt with M.Sss I and modification of placenta without dealing with M.Sss I); Marker (DL2000); M (MSP, methylated); U (USP, unmethylated). Area without strip is negative (-), area with strip is positive (+)Pathological samples (24-47), in which UGT1A1 genes all showed methylated positive except case 33 that showed unmethylated positive. 


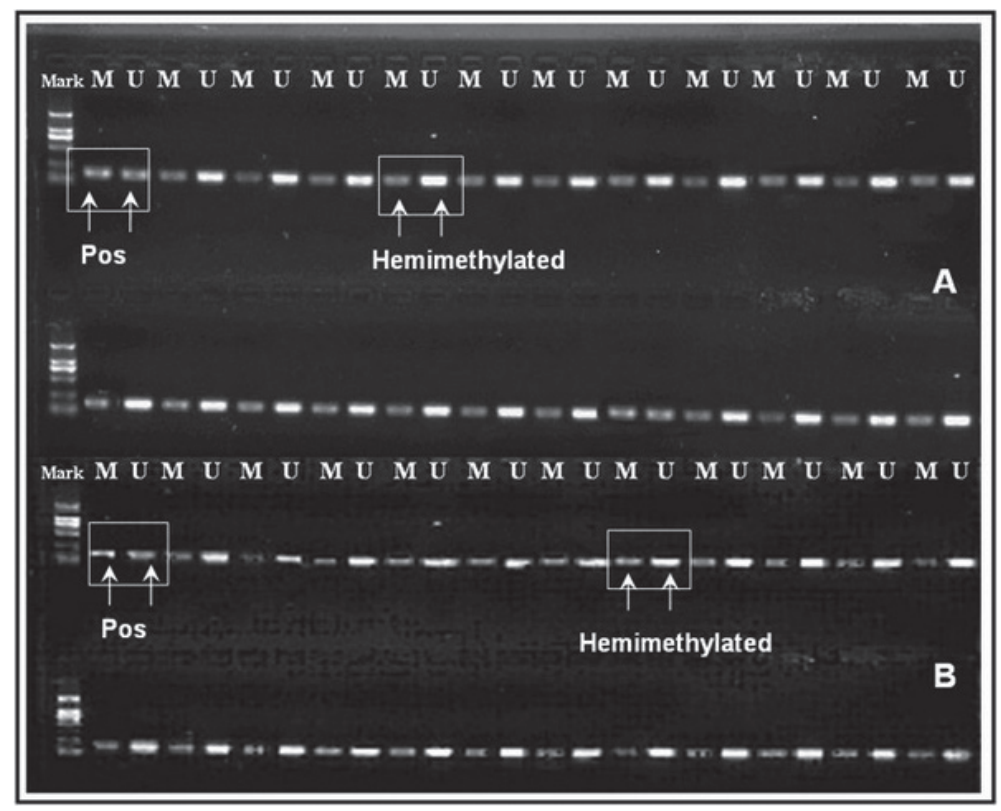

Figure 6. MSP Agarose Gel Electrophoresis of Colorectal Cancer Tissues and peritumorial normal tissues GUSB Gene (1.5\%). A. Colorectal Cancer Tissues (Number 1-23 Sample). B. peritumorial normal tissues (23 cases). Pos: positive control (Modification of placenta after been dealt with M.Sss I and modification of placenta without dealing with M.Sss I); Marker (DL2000); M (MSP, methylated); U (USP, unmethylated). Area without strip is negative (-), area with strip is positive (+).GUSB genes all showed hemimethylated

23). GUSB was hemimethylated in 59 colorectal cancer and in 23 paracancerous tissue samples. The expression of the GUSB gene, the regulatory ability of which needs to be verified, did not significantly differ between the hemimethylated samples. The potential role of this gene in colorectal cancer progression required in-depth research, and according to the results of the methylation-specific PCR, CES2 was not involved in the regulation of methylation. However, UGT1A1 gene methylation clearly correlated with the protein expression. When the gene was methylated, the protein expression was lower and vice versa. Moreover, the positive expression rate of colorectal cancer tissues was obviously higher than that of paracancerous normal tissues, which further indicated that the UGT1A1 methylation conditions of cancerous tissues were significantly different from those of normal tissues (Fig. 5). The UGT1A1 gene was methylated in 85 of the 99 colorectal cancer tissues, among which the high expression rate was $4.70 \%(4 / 85)$. The UGT1A1 gene was unmethylated in 14 cases, among which the high expression rate was $64.20 \%(9 / 14)$. A Spearman rank correlation was adopted to analyze the relationship between UGT1A1 gene methylation and protein expression, and the results showed that the methylation state and UGT1A1 gene expression were negatively correlated $(\mathrm{r}=-0.620)$.

\section{Discussion}

The CES2, GUSB, and UGT1A1 genes play an important role in regulating the in vivo metabolism of CPT-11. Carboxy-lesterase (CES), which is mainly distributed in the cell cytosol, mitochondria, and neoplasm, is a type of polyprotein that mainly catalyzes the hydrolysis of esters, sulfates, and amides $[12,13]$. The CES gene is located on 16q132 q22 of the human chromosome and exists in two forms, CES1 and CES2. It is highly conserved, especially CES2. The specific function of this type of enzyme has not yet been determined; however, carboxylesterases have been speculated to play a role in lipid metabolism and/or the blood-brain barrier system. An in vitro study has shown that CES2 plays a far

Table 5. Analysis result of gene methylation specific PCR of CES2, UGT1A1, GUSB

\begin{tabular}{llcccc}
\hline Types of tissues & & $\mathrm{N}$ & $\begin{array}{c}\text { UGT1A1 expression } \\
\mathrm{n}(\%)\end{array}$ & $\begin{array}{c}\text { CES2 expression } \\
\mathrm{n}(\%)\end{array}$ & $\begin{array}{c}\text { GUSB expression } \\
\mathrm{n}(\%)\end{array}$ \\
\hline \multirow{2}{*}{ Colorectal Cancer } & methylation & \multirow{2}{*}{99} & $85(86 \%)$ & $4(4 \%)$ & $99(100 \%)$ \\
& unmethylation & & $14(14 \%)$ & $95(96 \%)$ & - \\
\multirow{2}{*}{ Paracancerous normal } & methylation & 23 & $15(65 \%)$ & $23(100 \%)$ & - \\
& unmethylation & & $8(35 \%)$ & & - \\
\hline
\end{tabular}


more important role in the metabolism of Irinotecan than CES1 [14]. CES2 is the most important carboxy-lesterase in colorectal cancer and determines the hydrolysis of CPT- 11 . The individual differences in CES may be the reason for the difference in the curative effect and toxicity of CPT-11 [15]. Research shows that CES reformation plays a significant role in improving the effect of CPT-11, and it may become the goal of gene therapy for colorectal cancer [16]. UGT1A is an enzyme associated with the glucuronidation pathway that transforms small lipophilic molecules, such as steroids, bilirubin, hormones, and drugs, into water-soluble, excretable metabolites. The locus includes 13 unique alternate first exons, followed by four common exons. Four of the alternate first exons are considered pseudogenes. Each of the remaining nine 5' exons may be spliced into the four common exons, resulting in nine proteins with different $\mathrm{N}$-termini and identical C-termini. Each first exon encodes the substrate binding site and is regulated by its own promoter [17]. UGT1A1 is the only UGT genetic subtype that correlates with the bilirubin glucuronidation biological channels. By converting SN38 into an inactive compound, the UGT1A1 gene-coding enzymes protect the healthy cells from the toxicity of CPT-11. A report by Ratain from the University of Chicago demonstrated that the specific polymorphism expression of UGT1A1 genes of the patient serves as an important predictive index of serious leukocytopenia when treating with Irinotecan [18]. GUSB, a conserved housekeeping gene, participates in the catalysis of complex carbohydrates [19]. Human GUSB belongs to the glycosidase family, which is primarily involved in the hydrolysis process of the $\beta$-glucuronic acid residue from the non-reducing end. Human GUSB is located in the lysosome. In the gut, brush border GUSB converts conjugated bilirubin into the unconjugated form for re-absorption. The correlation between the expression of GUSB in tumor tissues and the sensitivity of CPT-11 is still disputed. Based on the roles that the CES2, UGT1A1, and GUSB genes play in the metabolism of CPT-11, they can possibly be used as the regulating and controlling target points for CPT-11 to increase its efficacy and drug resistance.

Currently, reports on the expression of CES2, UGT1A1, and GUSB in colorectal cancer tissues vary. A direct relationship between these three genes and the occurrence of tumors has not been reported, although recent correlation studies have been unified to a certain extent, i.e., the expression of GUSB does not differ between patients with colorectal cancer and healthy patients, while the expression of UGT1A1 and CES2 is somewhat related to the occurrence and development of tumors. Some studies [20] have reported that the change in UGT1A1 gene expression is directly related to the metastasis of colorectal cancer; additionally, the change in UGT1A1 can directly affect the mortality and recurrence rates of colorectal cancer in patients after receiving irinotecan treatment [21]. The increasing evidence that supports UGT1A1 as a potential target is worthy of attention, and our study also supports these findings. In addition, the relationship between CES2 and clinical staging has also been confirmed by similar reports, and studies have proven that CES2 expression is induced after the development of colorectal cancer and influences the development of colorectal cancer [22]. As such, the research direction of the UGT1A1 and CES2 genes as targets of the CPT-11 drug-resistance mechanism is feasible, but the role of methylation in the regulation of these two genes is currently unknown.

This study aimed to analyze the correlation of the respective expression levels of CES2, UGT1A1, and GUSB with clinical parameters by means of immunohistochemistry. The expression of CES2 was found to significantly differ between clinical stages $(\mathrm{P}<0.05)$. The clinical stage negatively correlated with CES2 expression. The chemotherapy effect of CPT-11-related metabolic enzymes cannot be judged by differences in the clinical stages alone. CES2, UGT1A1, and GUSB do not clearly correlate with gender, age, disease location, tumor differentiation, or other clinical indices. However, the expression levels of UGT1A1 and CES2 are specific, which suggests that they may somewhat correlate with the incidence of tumors and affect the development and stress effect of tumors. Furthermore, the mechanism responsible for the change in expression and potential interventions to artificially regulate it have not yet been determined.

Gagnon et al. determined that $82 \%$ of patients suffered from a lack of UGTIA mRNA expression [23] in a cohort of 50 patients with colorectal cancer. We aimed to confirm this finding with immunohistochemical staining, and the results showed that CRS2, UGT1A1, and GUSB were lowly expressed in colorectal cancer tissues. This expression level was even lower than that observed in adenoma and paracancerous tissues $(\mathrm{P}<0.05)$. The difference in expression levels between the different tissues suggested that the expressions of CES2 and UGT1A1 somewhat correlated with the incidence and development of the tumor. The literature has not yet reported evidence of CES2, UGT1A1, and GUSB as relevant metabolic enzymes of CPT-11. Samples that highly expressed CES2 or UGT1A1 often showed low expression of these same genes in their corresponding controls, which indicated a negative correlation and answered the aforementioned question that these two genes correlated with the incidence of tumors. Although the mechanism associated with this correlation requires further study. Furthermore, the involvement of methylation in the regulation of this process requires further investigation.

There is currently a dearth of studies in the literature concerning the epigenetic regulation of CES2, UGT1A1, and GUSB, which are the metabolic enzymes of CPT-11. However, the existing reports show that the expression of the metabolic enzymes of many drugs is regulated by DNA methylation [24]. The methylation and change in specific genes jointly drive colorectal adenomas toward the development of colorectal cancer [25]. Changes in specific DNA levels can serve as new screening biomarkers for colorectal cancer as well as a monitoring treatment for patients with colorectal adenoma [26]. Effective tests for the specific DNA methylation level present at the early stage of CPT-11 metabolism may be clinically sig- 
nificant for advanced colorectal cancer patients [20]. UGT1A1 has often been found to be methylated, and its role in tumor development is still unclear. The relationship between UGT1A1 methylation and clinical indicators has been researched, but statistically significant correlations have not been found between these two factors. Nevertheless, this is undoubtedly an important area for further study. If the regulation of UGT1A1 methylation can be demonstrated in other ways, it can be applied as a target point in this field. Furthermore, preliminary conclusions regarding CES2 and GUSB also require additional analysis to determine whether the methylation of CES2 and GUSB plays a role in treated colorectal cancer.

The MSP method can be used to prove our hypothesis to some extent and can serve as a direction for further research. The MSP test was performed in the present study in an attempt to demonstrate the possibility of regulating drug resistance by methylation via the correlations between the expression levels of CES2, UGT1A1, and GUSB in colorectal cancer tissues and abnormal methylation. The test results showed that 51 (51/59, $86.4 \%)$ colorectal cancer tissues exhibited changes in the methylation of the UGT1A1 gene, and 15 of the paracancerous normal tissues were UGT1A1 methylation-positive. A total of 49 of the 51 methylation-positive tissues showed deficient UGT1A1 expression, and their methylation levels significantly correlated with the corresponding protein expression $(\mathrm{P}<0.01)$. This finding indicates that methylation may be an important mechanism that causes deficient UGT1A1 expression in colorectal cancer, which can serve as a potential research target for regulating and controlling the drug resistance of CPT-11. Furthermore, future studies may focus on the regulation of the expression levels of CES2, UGT1A1, and GUSB in colorectal cancer by aberrant methylation and the influence of the methylation of target gene on the sensitivity of CPT-11 to further expand on this hypothesis. Studies that indicate the importance of the methylation of CES2 and GUSB in relevant colorectal cancer tissues have not yet been reported.

According to the results of the methylation-specific PCR, CES2 was not involved in the regulation of methylation. Therefore, methylation may not be responsible for the influence of CES2 on the metastasis of colorectal cancer. Thus, the results of the immunohistochemical test may indicate either a chain reaction caused by UGT1A1 and GUSB or that other regulatory points exist. Methylation status is therefore concluded to be irrelevant to the morbidity of colorectal cancer. We will further study the correlation between different regulation mechanisms of CES2 and UGT1A1 to explore whether these mechanisms can generate a cascade reaction. GUSB was generally in the hemimethylation state and did not correlate with the corresponding protein expression. GUSB is a type of mosaic gene with several loci of methylation at the intron and exon. Thus, it belongs to the class of multi-locus regulatory genes [27]. GUSB expression is stable, and its regulation is not subject to the adjustment of the methylation level of the promoter and genome itself [28]. A substantial methylation locus may have mutational loci at exons, causing the inactivation of the overall
GUSB expression level or part of the expression [27]. Thus, the degree of methylation of GUSB may not be fully presented in the qualitative experiment. Furthermore, the hemi-methylation may be fully presented, as methylation appeared in both tumor and normal samples, albeit to different degrees. GUSB can still serve as a regulatory target, which requires more indepth research. We hypothesize that GUSB may be indirectly regulated by UGT1A1 methylation.

In summary, this study identified differences in the expression of CES2, UGT1A1, and GUSB in colorectal pathological tissue, which confirms the correlation between CES2 expression and tumor staging. This relationship is likely caused by the regulation of the UGT1A1 and GUSB genes, although other regulatory mechanisms may exist. The methylation of the CES2 gene is relevant to the morbidity associated with colorectal cancer. GUSB gene expression did not significantly differ when the gene was hemi-methylated. The regulation ability of this gene still needs to be verified, and its potential role, which may be directly related to the methylation regulation of UGT1A1, requires further research. The methylation of the promoter of the UGT1A1 gene in colorectal cancer cells is an important mechanism of UGT1A1 gene silencing and can be considered the target of research associated with the CPT-11 drug-resistance mechanism. In addition, this study elucidated the role of aberrant methylation in the regulation of metabolic enzymes in colorectal cancer cells and ascertained the target points for further study of its mechanism and the function of drug sensitivity. These conclusions and approaches will provide important insight into the development of methods to reverse the drug-resistance of tumors and chemosensitization.

Acknowledgments: This study was supported by Natural Science Foundation of Fujian province of China(2010j01222).

\section{References}

[1] FEINBERG AP, VOGELSTEIN B. Hypomethylation distinguishes genes of some human cancers from their normal counterparts. Nature 1983; 301: 89-92. http://dx.doi. org/10.1038/301089a0

[2] KIM YI, GIULIANO A, HATCH KD, SCHNEIDER A, NOUR MA, et al. Global DNA hypomethylation increases progressively in cervical dysplasia and carcinoma. Cancer 1994; 74: 893-899. http://dx.doi.org/10.1002/1097-0142(19940801)74:3<893:: AID-CNCR2820740316>3.0.CO;2-B

[3] BEDFORD MT, VAN HELDEN PD. Hypomethylation of DNA in pathological conditions of the human prostate. Cancer research 1987; 47: 5274-5276.

[4] LIN CH, HSIEH SY, SHEEN I, LEE WC, CHEN TC, et al. Genome-wide hypomethylation in hepatocellular carcinogenesis. Cancer research 2001; 61: 4238.

[5] STRATHDEE G, MACKEAN M, ILLAND M, BROWN R. A role for methylation of the hmlh1 promoter in loss of hmlh1 expression and drug resistance in ovarian cancer. Oncogene 1999; 18: 2335. http://dx.doi.org/10.1038/sj.onc.1202540 
[6] EHRLICH M: DNA methylation in cancer. Too much, but also too little. Oncogene 2002; 21: 5400. http://dx.doi.org/10.1038/ si.onc. 1205651

[7] GAUDET F, HODGSON JG, EDEN A, JACKSON-GRUSBY L, DAUSMAN J, et al. Induction of tumors in mice by genomic hypomethylation. Science 2003; 300: 489-492. http://dx.doi. org/10.1126/science. 1083558

[8] LENGAUER C. An unstable liaison. Science 2003; 300: 442-443. http://dx.doi.org/10.1126/science. 1084468

[9] EDEN A, GAUDET F, WAGHMARE A, JAENISCH R. Chromosomal instability and tumors promoted by DNA hypomethylation. Science 2003; 300: 455-455. http://dx.doi. org/10.1126/science.1083557

[10] ASANO T, NAKAMURA K, FUJII H, HORICHI N, OHMORI $\mathrm{T}$, et al. Altered expression of topoisomerase iia contributes to cross-resistant to etoposide $\mathrm{k} 562 / \mathrm{mx} 2$ cell line by aberrant methylation. British journal of cancer 2005; 92: 1486-1492. http://dx.doi.org/10.1038/sj.bjc.6602498

[11] CARLINI LE, MEROPOL NJ, BEVER J, ANDRIA ML, HILL T, et al. Ugtla7 and ugtla9 polymorphisms predict response and toxicity in colorectal cancer patients treated with capecitabine/irinotecan. Clinical cancer research 2005; 11: 1226-1236.

[12] PAVILLARD V, AGOSTINI C, RICHARD S, CHARASSON V, MONTAUDON D, et al. Determinants of the cytotoxicity of irinotecan in two human colorectal tumor cell lines. Cancer chemotherapy and pharmacology 2002; 49: 329-335. http://dx.doi.org/10.1007/s00280-001-0416-0

[13] WIERDL M, TSURKAN L, HYATT J, EDWARDS C, HATFIELD M, et al. An improved human carboxylesterase for enzyme/prodrug therapy with cpt-11. Cancer gene therapy 2008; 15: 183-192. http://dx.doi.org/10.1038/ sj.cgt.7701112

[14] HUMERICKHOUSE R, LOHRBACH K, LI L, BOSRON WF, DOLAN ME. Characterization of cpt-11 hydrolysis by human liver carboxylesterase isoforms hce-1 and hce-2. Cancer research 2000; 60: 1189.

[15] SANGHANI SP, QUINNEY SK, FREDENBURG TB, SUN Z, DAVIS WI, et al. Carboxylesterases expressed in human colon tumor tissue and their role in cpt-11 hydrolysis. Clinical cancer research 2003; 9: 4983-4991.

[16] OOSTERHOFF D, OVERMEER RM, DE GRAAF M, VAN DER MEULEN I, GIACCONE G, et al. Adenoviral vector-mediated expression of a gene encoding secreted, epcam-targeted carboxylesterase- 2 sensitises colon cancer spheroids to cpt- 11 . British journal of cancer 2005; 92: 882-887. http://dx.doi. org/10.1038/sj.bjc.6602362

[17] RIBELLES N, LÓPEZ-SILES J, SÁNCHEZ A, GONZÁLEZ E, SÁNCHEZ M, et al. A carboxylesterase 2 gene polymorphism as predictor of capecitabine on response and time to progression. Current drug metabolism 2008; 9: 336-343. http://dx.doi. org/10.2174/138920008784220646
[18] INNOCENTI F, RATAIN MJ. Irinotecan treatment in cancer patients with ugtla1 polymorphisms. Oncology (Williston Park, NY) 2003; 17: 52.

[19] FUJIWARA R, NAKAJIMA M, YAMANAKA H, KATOH M, YOKOI T. Interactions between human ugtla1, ugtla4, and ugt1a6 affect their enzymatic activities. Drug Metabolism and Disposition 2007; 35: 1781-1787. http://dx.doi.org/10.1124/ dmd.107.016402

[20] CECCHIN E, INNOCENTI F, D'ANDREA M, CORONA G, DE MATTIA E, et al. Predictive role of the ugtla1, ugtla7, and ugtla9 genetic variants and their haplotypes on the outcome of metastatic colorectal cancer patients treated with fluorouracil, leucovorin, and irinotecan. Journal of Clinical Oncology 2009; 27: 2457-2465. http://dx.doi.org/10.1200/JCO.2008.19.0314

[21] PALOMAKI GE, BRADLEY LA, DOUGLAS MP, KOLOR $\mathrm{K}$, DOTSON WD. Can ugtlal genotyping reduce morbidity and mortality in patients with metastatic colorectal cancer treated with irinotecan? An evidence-based review. Genetics in Medicine 2009; 11: 21-34. http://dx.doi.org/ $\underline{10.1097 / G I M .0 b 013 e 31818 \text { efd77 }}$

[22] TANG X, WU H, WU Z, WANG G, WANG Z, et al. Carboxylesterase 2 is downregulated in colorectal cancer following progression of the disease. Cancer investigation 2008; 26: 178-181. http://dx.doi.org/10.1080/07357900701560786

[23] GAGNON JF, BERNARD O, VILLENEUVE L, TETU B, GUILLEMETTE C. Irinotecan inactivation is modulated by epigenetic silencing of ugtla1 in colon cancer. Clinical cancer research 2006; 12: 1850-1858. http://dx.doi.org/10.1158/10780432.CCR-05-2130

[24] FURBASS R, SELIMYAN R, VANSELOW J. DNA methylation and chromatin accessibility of the proximal cyp 19 promoter region $1.5 / 2$ correlate with expression levels in sheep placentomes. Molecular reproduction and development 2008; 75: 1-7. http://dx.doi.org/10.1002/mrd.20756

[25] BALIC M, PICHLER M, STRUTZ J, HEITZER E, AUSCH C, et al. High quality assessment of DNA methylation in archival tissues from colorectal cancer patients using quantitative high-resolution melting analysis. The Journal of molecular diagnostics: JMD 2009; 11: 102. http://dx.doi.org/10.2353/ jmoldx.2009.080109

[26] ZITT M, MULLER HM. DNA methylation in colorectal cancer-impact on screening and therapy monitoring modalities? Disease markers 2007; 23: 51-71. http://dx.doi. org/10.1155/2007/891967

[27] TOMATSU S, ORII KO, ISLAM MR, SHAH GN, GRUBB JH, et al. Methylation patterns of the human [beta]-glucuronidase gene locus: Boundaries of methylation and general implications for frequent point mutations at cpg dinucleotides. Genomics 2002; 79: 363-375. http://dx.doi.org/10.1006/geno.2002.6706

[28] ESTELLER M. Cpg island hypermethylation and tumor suppressor genes: A booming present, a brighter future. Oncogene 2002; 21: 5427. http://dx.doi.org/10.1038/sj.onc. 1205600 